\title{
Increasing the yield of Nebbiolo grapevines grown in acid soils: a comparison of different techniques
}

\author{
Roberto Merlo ${ }^{1}$, Leone Braggio ${ }^{l}$, Giacomo Nunin², Paolo Sivilotti ${ }^{2, *}$ \\ ${ }^{1}$ Uva Sapiens s.r.l., Via Rialto 3/4, 31010 Farra di Soligo, Treviso, Italy. \\ ${ }^{2}$ University of Udine, Department of Agricultural, Food, Environmental and Animal Sciences, Via delle Scienze 206, 33100 Udine, \\ Italy
}

\begin{abstract}
The detrimental effect of soil acidity on the performance of vines can be attributed to both $P$ deficiency and Al toxicity stresses. This study aimed to investigate the effect of different agronomical techniques applied in a vineyard of Nebbiolo to solve the problem of low productivity due to low soil $\mathrm{pH}$. The effect of liming, phosphorus fertilization and pre-bloom shoot trimming on yield and bud fruitfulness was followed over a period of 3 years. Moreover, in the last year of study grape analyses were performed to assess treatments' effect on grape quality. Results confirmed that it is possible to alleviate in part the low productivity due to low soil $\mathrm{pH}$. Overall, pre-bloom shoot trimming, $\mathrm{P}$ fertilization, and the combination of these two treatments have been the most effective options. Regarding the differences between treatments, only the combination of pre-bloom shoot trimming and P fertilisation significantly affected bud fruitfulness and yields in comparison to untreated. Little or no effect has been observed among treatments in terms of grape composition at harvest.
\end{abstract}

\section{Introduction}

Grapevines, as many other plants, can be grown in several conditions of soil, but as $\mathrm{pH}$ becomes too acid there are many implications for the productivity. Generally speaking, the vine does not perform well at $\mathrm{pH}$ values lower than 5,0 and stunted shoot growth as well as poor root growth may be symptoms [1].

The plants cultivated in acid soils suffer both phosphorus deficiency and aluminum toxicity stresses [2]. More than $80 \%$ of $\mathrm{P}$ in the soil is unavailable for plant uptake because of colloid adsorption, precipitation, or conversion to the organic form. $\mathrm{P}$ deficiency is the result of high fixation by aluminum and iron oxides and hydroxides [3]. Conradie [4] reported that the active absorption of $\mathrm{P}$ starts about three weeks after bud burst and stops at veraison, and a second peak period occurs from about five weeks after harvest until leaf fall. Phosphorous is the second most frequently limiting macronutrient for plant growth [5]. Reproductive development is more sensitive than vegetative development to $\mathrm{P}$ deficiencies [6]; phosphate deficiency is detrimental to inflorescence formation, and Skinner et al. [7] found that $P$ fertilization promoted an improvement of berry-set, which resulted in heavier clusters and thus increased yield.

The carbohydrate nutrition of the inflorescence at prebloom stage can markedly affect flower and cluster development and fruit set [8]. Leaves that have recently become source, initially export their assimilates to the growing shoot tip and unfolding leaves [9]. According to Hale and Weaver [8], shoot tips are more powerful sinks than the cluster during flower development but not during fruit set. Since clusters are unimportant sinks until bloom, shoot topping before or during bloom may improve fruit set because more assimilates are diverted into the developing clusters just prior to fruit set [10]. Moreover, hedging stimulates cross-transfer of assimilates to clusters on both sides of the shoot, and induces even young leaves to switch from upward to downward export [9].

In acid soils, clays are often saturated with a mixture of hydrogen and aluminum. Toxic levels of $\mathrm{Al}$ in the soils can be reduced by liming [11]. In addition to an increase in soil $\mathrm{pH}$ and the neutralization of exchangeable $\mathrm{Al}^{3+}$, other beneficial effects of liming soil are an increased $\mathrm{Ca}$ and $\mathrm{Mg}$ base saturation and $\mathrm{P}$ availability. The neutralization of exchangeable $\mathrm{Al}^{3+}$ by liming increases the response of plants to additions of P. This may be explained by better solubility and thereby better availability of $\mathrm{P}$ from Ca-phosphates compared to $\mathrm{Al}, \mathrm{Mn}$ and Fe-phosphates in acid soils [12].

An experiment was set up in a vineyard of Nebbiolo planted in Piedimont (Sperino, Biella) on acid soil, with the aim to find the best techniques to apply in order to obtain an increase of the yield compatible with the standard of Nebbiolo in other viticultural areas. Cluster fall and poor berry set are the major contributors to low yields due to high soil acidity; the applied techniques were intended to eliminate or lessen these phenomena.

\footnotetext{
* Corresponding author: paolo.sivilotti@uniud.it
} 


\section{Materials and methods}

\subsection{Plant material and experimental design}

The study was conducted on Vitis vinifera L. cv. Nebbiolo clone CVT 423 ("Picotendro") grafted onto Riparia Gloire rootstock during the seasons 2014, 2015 and 2016, at Proprietà Sperino Soc. Agr. (Lessona, Alto Piemonte, Italy). The vineyard is located on the pre-alpine plateau of Orolungo, in the district of Ori; the vines were planted in 2001 with a vine spacing of 2,2 $\mathrm{m}$ between rows and 0,9 $\mathrm{m}$ between vines (5050 vines/ha), and were trained using a Guyot training system.

The vineyard site is characterized by a well-drained acidic soil, consisting of silt and marine sands on quaternary fluvio-glacial sediments. The physical and chemical analyses of the soil are shown in Tab. 1. The soil present a low concentration of $\mathrm{P}, \mathrm{K}$, and organic matter, and the low CEC accounts for a scarce availability of nutrients for plant absorption. Moreover the low $\mathrm{pH}$ and the high concentration of aluminum surely contribute to further reduce the availability of phosphorous, detrimental condition for bud fertility and consequently for grapevine production.

Table 1. Physical and chemical analyses of the soil of the vineyard of Nebbiolo.

\begin{tabular}{|l|c|}
\hline \multicolumn{2}{|l|}{ Physical properties } \\
\hline Coarse fraction (\%) & 5,6 \\
\hline 2-mm sieved fraction & 17,2 \\
\hline Sand (\%) & 61,7 \\
\hline Silt (\%) & 21,1 \\
\hline Clay (\%) & SICLLO \\
\hline Soil classification & 4,0 \\
\hline Chemical properties & 10,4 \\
\hline pH & 4 \\
\hline CEC (meq/100g) & 73 \\
\hline P (ppm) & 1530 \\
\hline K (ppm) & 60,6 \\
\hline Ca (ppm) & 0,9 \\
\hline Al (mg/kg) & \\
\hline Organic matter (\%) & \\
\hline
\end{tabular}

A completely randomized experimental design was arranged within the vineyard, with 8 treatments, 3 replicates for each treatment and 5 vines/replicate. The treatments are described in detail in Tab. 2.

Pre-bloom shoot trimming (PBST) was performed ca 10 days before flowering time, while lime and phosphorous were added during winter time at 10 tonns/ha (Li 10), 20 tonns/ha (Li20) or $100 \mathrm{~kg} / \mathrm{ha}(\mathrm{P})$.

\subsection{Yield parameters and bud fruitfulness}

Shoot and cluster number was evaluated on all 5 vines of each plot during both pre- and post-bloom time; shoots originated from the cane and from the left spur on the grapevine head were examined separately. At harvest time yield and cluster number were evaluated for each plot, and the average cluster weight computed by rating the yield by the number of clusters. The bud fruitfulness was calculated rating the number of clusters by the number of shoots developed on the canes (shoots and clusters originated on the spurs were removed from the calculation).

Table 2. details and labels of the treatments under comparison.

\begin{tabular}{|l|l|}
\hline Labels & Treatments detail \\
\hline UNT & Control untreated \\
\hline Li 10 & Lime 10 tonns/ha \\
\hline Li 20 & Lime 20 tonns/ha \\
\hline PBST & Pre-bloom shoot trimming \\
\hline P & Phosphorus $\left(\mathrm{P}_{2} \mathrm{O}_{5}\right) 100 \mathrm{~kg} / \mathrm{ha}$ \\
\hline Li 10+ PBST & $\begin{array}{l}\text { Lime } 10 \text { tonns } / \text { ha }+ \text { Pre-bloom shoot } \\
\text { trimming }\end{array}$ \\
\hline Li 10+ P & Lime 10 tonns $/$ ha $+\mathrm{P}_{2} \mathrm{O}_{5} 100 \mathrm{~kg} / \mathrm{ha}$ \\
\hline P + PBST & $\begin{array}{l}\mathrm{P}_{2} \mathrm{O}_{5} 100 \mathrm{~kg} / \mathrm{ha}+\text { Pre-bloom shoot } \\
\text { trimming }\end{array}$ \\
\hline
\end{tabular}

\subsection{Statistical analysis}

Data were analyzed through full-factorial two-ways ANOVA; levels of significance in tables and graphs are given as ns, *,**, *** for not significant, significant at $\mathrm{p}<0,05, \quad \mathrm{p}<0,01$, and $\mathrm{p}<0,001$, respectively. When ANOVA was significant, differences among seasons were separated using Tukey's test; values followed by the same letter within a column are not significantly different at $\mathrm{p}<0,05$. Regarding the differences between treatments, orthogonal comparisons were performed using contrast analysis between each treatment and the untreated, and the significance of the differences $(\mathrm{p}<0,05)$ are reported.

\section{Results}

Analysis of variance highlighted significant differences between UNT and treated vines in terms of number of clusters at pre and post-bloom, bud fruitfulness and yield per vine (Tab. 3).

In most cases, the applied techniques caused an increase in bud fruitfulness with the exception of Li10, $\mathrm{Li} 20$ and $\mathrm{Li} 10+\mathrm{P}$ treatments. PBST $+\mathrm{P}$ treatment with an increase of $20,6 \%$ was the most effective on bud fruitfulness, while $\mathrm{P}$ addition, PBST and Li10+PBST increased this parameter to a lesser extent. Liming did not improve bud fruitfulness when applied alone or together with $\mathrm{P}$. Mean pairwise comparisons demonstrated that only $\mathrm{PBST}+\mathrm{P}$ treatment significantly increase bud fruitfulness in comparison to untreated (Tab. 3). 
Table 3. Effect of treatments and year on the different parameters examined in this study.

\begin{tabular}{|c|c|c|c|c|c|c|c|c|}
\hline Factor & Level & 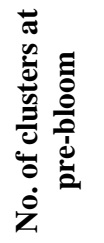 & 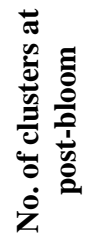 & 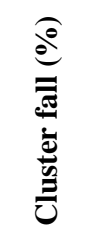 & 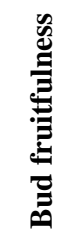 & 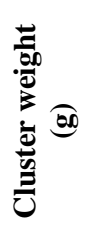 & 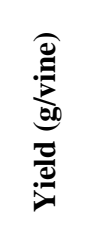 & 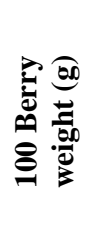 \\
\hline \multirow[t]{9}{*}{ Treatment } & UNT & 6,57 & 6,36 & 3,06 & 0,59 & 228 & 1496 & 167 \\
\hline & Li10 & 6,05 & 5,93 & 1,99 & 0,50 & 224 & 1327 & 162 \\
\hline & Li20 & 6,67 & 6,19 & 5,73 & 0,57 & 231 & 1437 & 161 \\
\hline & PBST & 6,71 & 6,38 & 4,40 & 0,62 & 246 & 1543 & 162 \\
\hline & $\mathrm{P}$ & 6,76 & 6,73 & 0,61 & 0,67 & 231 & 1562 & 152 \\
\hline & Li10 + PBST & 7,42 & 7,27 & 2,08 & 0,69 & 243 & 1825 & 165 \\
\hline & $\mathrm{Li} 10+\mathrm{P}$ & 6,88 & 6,39 & 8,56 & 0,58 & 234 & 1612 & 161 \\
\hline & PBST + P & 8,69 & 8,05 & 6,65 & 0,71 & 242 & 1951 & 159 \\
\hline & $\operatorname{sign.} F^{a}$ & $*$ & $*$ & $n s$ & $* *$ & $n s$ & $*$ & $n s$ \\
\hline
\end{tabular}

contrasts significance

$\begin{array}{llllll}\text { UNT vs Li10 } & n s & n s & n s & n s & n s \\ \text { UNT vs Li20 } & n s & n s & n s & n s & n s \\ \text { UNT vs PBST } & n s & n s & n s & n s & n s \\ \text { UNT vs P } & n s & n s & n s & n s & n s \\ \text { UNT vs (Li10 + PBST) } & n s & n s & n s & n s & n s \\ \text { UNT vs (Li10 + P) } & n s & n s & n s & n s & n s \\ \text { UNT vs (PBST +P) } & * * & * * & * * & n s & *\end{array}$

Year

$\begin{array}{lccccccc}2014 & 6,10 \mathrm{~b}^{\mathrm{b}} & 5,83 \mathrm{~b} & 3,91 & 0,48 \mathrm{~b} & 224 \mathrm{~b} & 1337 \mathrm{~b} & 154 \mathrm{~b} \\ 2015 & 7,38 \mathrm{a} & 6,96 \mathrm{a} & 5,45 & 0,70 \mathrm{a} & 183 \mathrm{c} & 1301 \mathrm{~b} & 171 \mathrm{a} \\ 2016 & 7,39 \mathrm{a} & 7,16 \mathrm{a} & 2,89 & 0,67 \mathrm{a} & 297 \mathrm{a} & 2138 \mathrm{a} & 158 \mathrm{~b} \\ \text { sign. F } & * * * & * * * & n s & * * * & * * * & * * * & * * *\end{array}$

Interaction T x Y sign.F $\quad n s \quad n s \quad n s \quad n s \quad n s \quad n s \quad n s$

${ }^{a}$ Data were analyzed through full-factorial two-way ANOVA (ns, not significant; $\left.*, p<0,05 ; *^{*}, \mathrm{p}<0,01 ; * * *, p<0,001\right)$, and when differences were significant, the season means were separated using Tukey's test $(p<0,05)$, while in case of the treatments contrast analysis between each treatment and the untreated was used ( $p<0,05)$.

${ }^{b}$ Different letters identify significantly different means. Li 10, lime 10 tons/ha; Li 20, lime 20 tons/ha; PBST, pre-boom shoot trimming; P, phosphorus.

Li 10 was the only treatment showing a decrease in cluster number $(-7,9 \%)$ before flowering, while in the other cases higher cluster number was obtained. Addition of $\mathrm{P}$ along with PBST caused the higher positive variation, followed by Li10+PBST and Li10+P. In comparison to the control, the only significant difference was found for
PBST $+\mathrm{P}$ treatment, which accounted for an increase of $32,4 \%$ compared to the control. At post-bloom, cluster number was positively affected by all treatments with the exception of lime addition. PBST $+\mathrm{P}$ and PBST $+\mathrm{Li10}$ treatments showed lower levels of cluster fall, recording respectively $26,6 \%$ and $14,3 \%$ more clusters compared 
with the control. Again, P+PBST was the only treatment reporting significant higher values as compared to untreated vines.

Cluster fall shows the reduction in cluster number that occurred between pre and post-bloom. Applied agronomical techniques did not impact cluster fall. Control untreated presented $3,06 \%$ of cluster fall. In general, a reduction of cluster fall was seen in Li10, $\mathrm{P}$ and Li $10+$ PBST.

Berry and cluster weight were not significantly affected by treatments (Tab. 3). In general, although mean results did not differ significantly, the treated vines showed a tendency towards lower values of berry weight and higher values of cluster weight. Contrast analysis confirmed that data collected were not significantly different against untreated.

Yield was significantly affected by treatments. PBST $+\mathrm{P}$ and Li10+PBST increased yield more than the other techniques. Liming did not promote a positive effect on yields. As for other parameters, the treatment PBST $+\mathrm{P}$ resulted in significantly higher yield as compared to untreated.

The season significantly modified all parameters of the study (Tab. 3). As regard the number of clusters and the bud fruitfulness, in the first season (2014) the values were significantly lower, while no differences between the other two seasons could be appreciated. As opposite, the average cluster weight was significantly the lowest in 2015, intermediate in 2014 and the highest in 2016. Significantly higher yield was shown in the last season, while similar values were ascertained in the other two seasons. The lowest value of average cluster weight in 2015 was also related with the lower significant value of berry weight.

\section{Discussion}

There are several processes involved in the formation of acid soils. The majority of acid soils originate in areas characterized by heavy rainfall; in fact, the acidification process is strictly dependent on the amount of water that pass through the soil profile. Exchangeable basic cations $\left(\mathrm{Ca}^{2+}, \mathrm{Mg}^{2+}, \mathrm{K}^{+}\right)$of clay minerals are leached out by water; they are so substituted with hydrogen and aluminum ions, which neutralize negative charges of colloids. More than $95 \%$ of mineral soils' acidity is attributed to hydrogen and aluminum. Other important causes of soil acidification are root and microbial respiration, mineralization and nitrification processes, organic acids release from vegetation, abundancy of soil organic matter and plant roots.

As reviewed in the introduction, plants growing in acid soils suffer both $\mathrm{P}$ deficiency and aluminum toxicity stresses. The plants developed different morphological and physiological mechanisms to cope with soil $\mathrm{P}$ limitation, such as the development of root hairs and association of the roots with vesicular-arbuscular mycorrhizae. Moreover, bound inorganic $\mathrm{P}$ can be released by the exudation of organic acids (improved with citrate), which allows for the displacement of $\mathrm{P}$ from $\mathrm{Al}^{3+}$, $\mathrm{Fe}^{3+}$ and $\mathrm{Ca}^{2+}$ phosphates [13]. In addition to $\mathrm{P}$ fixation,
$\mathrm{Al}$ reduces root growth and affects nutrient translocation by plants. Morlat and Jacquet [14] confirmed that the root density was noticeably lower in case of sandy acid soils, because of both strong acidity and high concentration of manganese, which creates unfavorable conditions for rooting. Himelrick [15] reported that $\mathrm{P}$ and $\mathrm{Ca}$ levels were always higher in the plants grown in soils with higher $\mathrm{pH}$, while $\mathrm{Mg}, \mathrm{Fe}, \mathrm{Cu}$, and $\mathrm{Zn}$ levels showed an opposite trend.

In the present experiment, the yield/vine was really low, basically because of the poor fertility impaired by the acid $\mathrm{pH}$. As described in the results, different techniques were applied with the aim to increase yield, exploiting different mechanisms.

As reported by Singleton et al. [11], one possibility to attenuate the toxic effect of aluminum in the soil is the application of lime, as $\mathrm{CaCO}_{3}$ reacts with carbonic acid to form calcium bicarbonate, a more soluble and leachable intermediate. The calcium bicarbonate ionizes so that its calcium ions are able to replace hydrogen and aluminum ions on the exchange sites of clay particles. This means an increased base saturation, increased $\mathrm{pH}$, and a loss of hydrogen ions.

Since in the present vineyard the soil $\mathrm{pH}$ was really low, we decided to apply significant amounts of lime (10 or 20 tonns/ha), but no significant increase of yield was obtained. On the contrary, a slight reduction of yield can be shown in case of the lower lime rate over three years of treatments. To date, soil has a huge buffering capacity counteracting the effects of all kinds of amendments [16]. Moreover, the root system could end deeper than the liming treatment, where the $\mathrm{pH}$ value drops and the $\mathrm{Al}^{3+}$ concentration becomes relatively important [17]. Thus, both conditions could help to explain the poor effect of lime on increasing yield.

Another technique applied in the present experiment was pre-bloom shoot thinning, with the aim to increase the berry-set and so the average cluster weight. During the first part of the seasons, the strongest sinks for the plant are represented by the shoot tips. Considering a rapidly growing shoot as a whole, the translocation in the terminal portion is acropetal only: movement of photosynthates from the two or three youngest exporting leaves is almost exclusively to the shoot tips. While the removal of mature leaves reduces set in grapes [18], topping and pinching are known to increase set if done during flowering [10]. Moreover, hedging stimulates cross-transfer of assimilates to clusters on both sides of the shoot and induces even young leaves to switch from upward to downward export [9]. This is probably why shoot topping during bloom often improves fruit set. In the present trial, PBST promoted a timid increase of yield, due to the slight increase of berry-set (expected) and so cluster weight. Still, not significant difference from the UNT was found, and probably another solution providing an increase of the cluster number needed to be found in order to get a better result.

The third technique considered in the present trial, was the application of a high rate of phosphorous, aiming to increase the bud fruitfulness and so the number of clusters growing on the shoots. Skinner and Matthews [6] reported that withholding $\mathrm{P}$ at bloom and veraison, a significant 
decrease in berry number, cluster weight and the number of cluster primordial occurred. Initiation, differentiation and maintenance of reproductive primordia are sensitive to $\mathrm{P}$ supply throughout the season, being the maintenance of initiated clusters more sensitive than initiation of clusters [6]. In the present experiment, also P treatment contributed with a timid increase of yield, caused by a slightly higher number of clusters remained postflowering, partially compensated by a reduction in berry weight.

\section{Conclusion}

The three techniques applied alone, did not promote sensible modifications in the yield parameters as expected. Differently, more interesting effects were ascertained when the techniques were combined. In detail, the combination of Li10 with $\mathrm{P}$ or with PBST, was profitable to promote an increase of yield, mainly in the second treatment. At last, the combination of PBST and P fertilization was the most interesting technique, that allowed maintaining the higher number of grapes on the vines without reducing the berry-set.

The results of the experiment here presented highlight that acid soils are not properly suitable for the cultivation of grapes, since the low $\mathrm{pH}$ negatively affects the yield. Anyway, the application of suitable techniques, such as pre-bloom shoot thinning and $\mathrm{P}$ fertilization could partially offset the problem by increasing the bud fruitfulness and percentage of berry-set. These techniques applied together provided the only significant increase of the yield observed in the present experiment over three years of trial, and thus they represent a sustainable viticultural solution for the winegrowers of this area.

In future experiments, analyses of leaf concentration of $\mathrm{P}, \mathrm{Al}$, and $\mathrm{Ca}$ would be important in order to understand the effects of different treatments on plant mineral absorption, and explain why and how an increase of yield can be obtained.

\section{References}

1. W.J. Conradie. S. Afr. J. Enol. Vitic 4, 39-44 (1983).

2. M. Jemo, R.C. Abaidoo, C. Nolte, W.J. Horst. J. Plant Physiol. 164, 442-451 (2007).

3. R.L. Parfitt. J. Soil Sci. 40, 359-369 (1989).

4. W.J. Conradie. S. Afr. J. Enol. Vitic. 2, 7-13 (1981).

5. D.P. Schachtman, R.J. Reid, S.M. Ayling. Plant Physiol. 116, 447-453 (1998).

6. P.W. Skinner, M.A. Matthews. Sci. Hortic. 38, 4960 (1989).

7. P.W. Skinner, J.A. Cook, M.A. Matthews. Vitis 27, 95-10 (1988).

8. C.R. Hale, R.J. Weaver. Hilgardia 33, 89-131 (1962).

9. Keller, M. The science of grapevines. (Elsevier Inc. 2010).

10. B.G. Coombe. Am. J. Enol. Vitic. 10, 85-100 (1959).
11. P.L. Singleton, D.C. Edmeades, R.E. Smart. New Zeal. J. Agric. Res. 30, 517-522 (1987).

12. L. Čoga, M.H. Ćustić, I. Pavlović. Agric. Conspec. Sci. 74, 39-43 (2009).

13. C.L. Ward, A. Kleinert, K.C. Scortecci, V.A. Benedito, A.J. Valentine. J. Plant Physiol. 168, 459-465 (2011).

14. R. Morlat, A. Jacquet. Vitis 32, 35-42 (1993).

15. D.G. Himelrick. HortScience 26, 269-271 (1991).

16. S. J. Zheng S.J. Ann. Bot., 106, 183-184 (2010).

17. B.R. Meyer, E. Le Roux, M.J. Renan, M. Peisach. Nucl. Instrum. Methods Phys. Res. B 3, 557-560 (1984).

18. M. Sternad Lemut, P. Sivilotti, L. Butinar, J. Laganis, U. Vrhovšek Aust. J. Grape Wine Res. 21, 439-450 (2015). 